\title{
Meperidine (pethidine) versus morphine in acute pain management of opioid-dependent patients
}

This article was published in the following Dove Press journal:

Open Access Emergency Medicine

31 August 2016

Number of times this article has been viewed

\author{
Hassan Solhi' \\ Hossein Sanaei-Zadeh ${ }^{2}$ \\ Sadra Solhi' \\ Mohammad Ali Azizi \\ Nadian' \\ Morteza Gharibi ${ }^{3}$ \\ Bahman Sadeghi Sedeh ${ }^{4}$ \\ 'Department of Internal Medicine, \\ Arak University of Medical Sciences, \\ Arak, ${ }^{2}$ Emergency Room, Division \\ of Medical Toxicology, Hazrat \\ Ali-Asghar (p) Hospital, Shiraz \\ University of Medical Sciences, Shiraz, \\ ${ }^{3}$ Department of Emergency Medicine, \\ Arak University of Medical Sciences, \\ ${ }^{4}$ Department of Social Medicine, \\ Arak University of Medical Sciences, \\ Arak, Iran
}

\begin{abstract}
The present study aimed to evaluate the effectiveness of morphine and meperidine (pethidine) as pain relief in opioid-dependent patients with acute pain. A total of 122 opioiddependent patients with acute pain were included in the study. Their pain severity was assessed, using visual analog scale (VAS) scores ranging from 0 to 10 . The patients randomly received intravenous morphine (up to $0.15 \mathrm{mg} / \mathrm{kg}$ ) or meperidine (up to $1.5 \mathrm{mg} / \mathrm{kg}$ ) for pain control by patient control analgesia (PCA) pump. The clinical opioid withdrawal scale (COWS) was employed for the assessment of withdrawal symptoms. The pain relief and the emergence of withdrawal symptoms were measured at 15,30 , and 60 minutes after drug administration. The patients who received morphine reported a better pain control compared to those who received meperidine (mean \pm standard deviation [SD] VAS scores $4.11 \pm 1.90$ vs $5.85 \pm 2.08$ at the end of the study; $P<0.001)$. On the other hand, the patients who received meperidine indicated prominent withdrawal symptoms (mean \pm SD COWS scores $4.80 \pm 2.18$ vs. $1.98 \pm 0.82$ at the end of the study; $P<0.001)$. Our findings revealed that morphine can be recommended in acute pain management of opioid-dependent patients. In addition, emergency physicians should ask their patients about any drug dependence before selecting the appropriate drug for their acute pain management.
\end{abstract}

Keywords: pain management, meperidine, morphine, opioid dependency, withdrawal symptoms

\section{Introduction}

Pain is a major medical problem. The physiological and psychological consequences of acute and chronic pain are well-recognized. ${ }^{1-3}$ Inadequately treated pain can lead to detrimental physiological consequences and may also have psychological, economic, and social adverse effects. Effective pain control is desirable on humanitarian grounds, as well as for its potential to improve patients' recovery, rehabilitation, and outcome. . $^{2,3}$ Acute pain can also increase heart rate and blood pressure, suppress immune functioning, and reduce pulmonary function, leading to an increased risk of dangerous complications, including myocardial ischemia, deep vein thrombosis, pulmonary embolism, hypoxia, pneumonia, and stroke. ${ }^{4-6}$ Current treatment options for the management of acute pain in the emergency department (ED) encompass opioid analgesics such as morphine, hydromorphone, or fentanyl and non-opioid analgesics such as acetaminophen, ketamine, local anesthetics, and non-steroidal anti-inflammatory drugs. ${ }^{2}$

Opioids have been utilized for thousands of years to treat pain and still continue to be one of the most commonly prescribed medications for acute pain management in the ED. ${ }^{2}$ Morphine is the standard opium-based analgesic with well-known analgesic effects and side effects. ${ }^{7}$ Meperidine (pethidine) is another opioid, but the use
Correspondence: Hossein Sanaei-Zadeh Emergency Room, Division of Medical Toxicology, Hazrat Ali-Asghar (p) Hospital, Meshkinfam Street, 7|43918796, Shiraz University of Medical Sciences, Shiraz, Iran

Tel +98 7I3228 8604

Fax +987132288907

Email sanaeizadeh@sums.ac.ir 
of meperidine is not very popular in countries such as the USA and Canada, however it is still used in Iran for pain management in the ED. ${ }^{7,8}$ In our country, Iran, the only opioids that can be parenterally used in the ED for acute pain management are meperidine, morphine, and fentanyl. There are few studies that have compared the analgesic effects of meperidine and morphine in non-opioid-dependent patients. ${ }^{9}$ However, thus far no study has been conducted to compare the effectiveness and the side effects of morphine and meperidine for acute pain management in the opioiddependent patients. The present study was designed to clarify this issue.

\section{Materials and methods}

Of the 20- to 60-year-old opioid-dependent patients who presented to the ED of Hazrat Valiasr Hospital in Arak, Iran for acute pain control between March 20, 2012 and September 21, 2012, 122 patients were randomly selected. These patients were dependent on methadone, heroin, opium, opium dross, or refined opium dross (Shireh). In case of suspected acute abdomen, hypotension, head trauma, liver diseases, decreased renal function, and earlier administration of any drugs for pain relief prior to the ED presentation, the patients were excluded from our study. Pain severity was assessed, using visual analog scale (VAS) scores ranging from 0 to 10 . The patients randomly received intravenous morphine (up to 0.15 $\mathrm{mg} / \mathrm{kg}$ ) or meperidine (up to $1.5 \mathrm{mg} / \mathrm{kg}$ ) for pain control by patient control analgesia (PCA) pump. Pain relief and emergence of withdrawal symptoms were assessed at 15, 30, and 60 minutes after drug administration. The clinical opioid withdrawal scale (COWS) was employed for the evaluation of withdrawal symptoms in the patients. The study was approved by the local ethical committee of Arak University of Medical Sciences. All of the patients provided written consent forms. The results were analyzed by SPSS software version 16.0 using Student's $t$-test. The statistical significance was set at $P<0.05$.

\section{Results}

A total of 122 patients were assigned into two 61-patient groups. The mean VAS scores of the groups are demonstrated in Table 1 . The severity of withdrawal symptoms during the study is illustrated in Table 2. As demonstrated in the tables, the patients who received morphine reported a better pain control compared to those who received meperidine (mean \pm SD VAS scores $4.11 \pm 1.90$ vs $5.85 \pm 2.08$ at the end of the study; $P<0.001)$. On the other hand, patients who received meperidine showed prominent withdrawal symptoms (mean \pm SD COWS scores $4.80 \pm 2.18$ vs $1.98 \pm 0.82 ; P<0.001)$.
Table I Mean ( \pm SD) visual analog scale scores of the studied groups at the start of the study and thereafter

\begin{tabular}{llll}
\hline Assessment time & $\begin{array}{l}\text { Morphine } \\
\text { group }\end{array}$ & $\begin{array}{l}\text { Meperidine } \\
\text { group }\end{array}$ & P-value \\
\hline Start of the study & $7.34 \pm 1.75$ & $8.06 \pm 1.50$ & 0.073 \\
I5 minutes after drug therapy & $7.12 \pm 1.71$ & $7.50 \pm 1.65$ & 0.065 \\
30 minutes after drug therapy & $6.50 \pm 1.84$ & $7.27 \pm 1.61$ & $<0.001$ \\
60 minutes after drug therapy & $4.11 \pm 1.90$ & $5.85 \pm 2.08$ & $<0.001$ \\
\hline
\end{tabular}

Abbreviation: SD, standard deviation.

Table 2 Mean $( \pm$ SD) clinical opioid withdrawal scale scores in the studied groups during the study

\begin{tabular}{llll}
\hline Assessment time & $\begin{array}{l}\text { Morphine } \\
\text { group }\end{array}$ & $\begin{array}{l}\text { Meperidine } \\
\text { group }\end{array}$ & P-value \\
\hline Start of the study & none & none & - \\
15 minutes after drug therapy & $1.98 \pm 0.82$ & $2.14 \pm 0.83$ & 0.278 \\
30 minutes after drug therapy & $1.98 \pm 0.82$ & $3.00 \pm 1.01$ & $<0.001$ \\
60 minutes after drug therapy & $1.98 \pm 0.82$ & $4.80 \pm 2.18$ & $<0.001$ \\
\hline
\end{tabular}

Abbreviation: SD, standard deviation.

\section{Discussion}

In addition to methadone that is orally used in methadone maintenance treatment programs and heroin that is intravenously or inhalationally abused, opium, opium dross, and refined opium dross (Shireh) are the opioids commonly abused in Iran orally or inhalationally. ${ }^{10,11}$ Shireh is usually made by boiling opium dross (left in pipes after smoking opium) or a mixture of opium and opium dross with water which is filtered several times. The filtrate is evaporated until a gummy consistency is achieved..$^{10}$

It has been stated that acute pain management is a challenge in opioid-dependent patients since they are often undertreated for pain. Therefore, in acute pain management in these patients, an appropriate opioid with an appropriate dosage should be given to them to control the pain and prevent the development of withdrawal symptoms. ${ }^{12,13}$

The present study compared the effectiveness of morphine and meperidine in the management of acute pain as well as the development of withdrawal symptoms in the patients. The results confirmed that meperidine was less effective in acute pain management compared to morphine. Moreover, it was found that meperidine might produce withdrawal symptoms which complicated the patients' situation more than before.

To date, a number of studies have been performed that have compared the analgesic effects of meperidine and morphine via PCA in non-opioid-dependent patients, indicating that meperidine can only control mild pain in comparison with morphine. ${ }^{9}$ Our study also suggested that pain control was not successful in meperidine group. It was also revealed that patients who received meperidine experienced more withdrawal, while meperidine is a pure agonist and should not cause withdrawal per se. ${ }^{7}$ As mentioned above, insufficient 
doses of opioid not only undertreat the pain, but also cannot prevent withdrawal symptoms in opioid-dependent patients. ${ }^{12}$ Therefore, pain can affect the COWS parameters and increase this score in the studied population.

According to our findings, we recommend using morphine, rather than meperidine, in acute pain management of opioid-dependent patients. Emergency physicians should query their patients about any drug dependence before selecting the appropriate drug for their acute pain management.

\section{Disclosure}

The authors report no conflict of interests in this work.

\section{References}

1. Kuehn BM. Opioid prescriptions soar increase in legitimate use as well as abuse. JAMA. 2007; 297(3):249-251.

2. Motov SM, Nelson LS. Advanced Concepts and Controversies in Emergency Department Pain Management. Anesthesiol Clin. 2016;34(2):271-285.

3. Green SM. There is oligo-evidence for oligoanalgesia. Ann Emerg Med. 2012;60(2):212-214.

4. Breivik H. Postoperative pain management: why is it difficult to show that it improves outcome? Eur J Anaesthesiol. 1998;15(6):748-751.
5. Macintyre PE, Schug SA, Scott DA, Visser EJ, Walker SM, APM:SE Working Group of the Australian and New Zealand College of Anaesthetists and Faculty of Pain Medicine. Acute Pain Management: Scientific Evidence, 3rd ed. Melbourne: ANZCA \& FPM, 2010. Available from: https://www.nhmrc.gov.au/guidelines-publications/cp104.

6. Spacek A. Modern concepts of acute and chronic pain management. Biomed Pharmacother. 2006;60(7):329-335.

7. Olsen D, Nelson LS. Opioids. In: Hoffman RS, Howland MA, Lewin NA, Nelson LS, Goldfrank LR, eds. Goldfrank's Toxicologic Emergencies. 10 $0^{\text {th }}$ ed. New York, New York: McGraw-Hill, 2015: 492-509.

8. Fisher JE, Zhang Y, Sketris I, Johnston G, Burge F. The effect of an educational intervention on meperidine use in Nova Scotia, Canada: a time series analysis. Pharmacoepidemiol Drug Saf. 2012;21(2):177-183.

9. Latta KS, Ginsberg B, Barkin RL. Meperidine: a critical review. Am J Ther. 2002;9(1):53-68.

10. Farsinejad M, Sanaei-Zadeh H. Methadone detoxification versus traditional gradual decrease in the consumed amount of refined opium dross (Shireh): The preferred method for controlling withdrawal syndrome. Iranian Journal of Toxicology. 2012; 7(17): 638-641.

11. Zamani N, Sanaei-Zadeh H, Mostafazadeh B. Hallmarks of opium poisoning in infants and toddlers. Trop Doct. 2010;40(4):220-222.

12. Kraft L, Wiechula R, Conroy $\mathrm{T}$. The effectiveness of acute pain management for opioid tolerant or opioid dependent patients: a systematic review protocol. JBI Database System Rev Implement Rep. 2015;13(9):120-135.

13. Pallasch TJ. Anesthetic management of the chemically dependent patient. Anesth Prog. 1992;39(4-5):157-161.
Open Access Emergency Medicine

\section{Publish your work in this journal}

The Open Access Emergency Medicine is an international, peerreviewed, open access journal publishing original research, reports, editorials, reviews and commentaries on all aspects of emergency medicine. The manuscript management system is completely online and includes a very quick and fair peer-review system, which is all
Dovepress

easy to use. Visit http://www.dovepress.com/testimonials.php to read real quotes from published authors. 